\title{
ANALISIS DISTRIBUSI GAYA AKSIAL PADA FONDASI TIANG RAKIT AKIBAT PERBEDAAN KEDALAMAN TIANG DAN PENURUNAN
}

\author{
Jovito Charless $^{1}$ dan Alfred Jonathan Susilo ${ }^{2}$ \\ ${ }^{1}$ Program Studi Sarjana Teknik Sipil, Universitas Tarumanagara, Jl. Letjen S. Parman No.1 Jakarta \\ Email: jovitocharless@hotmail.com \\ ${ }^{2}$ Program Studi Sarjana Teknik Sipil, Universitas Tarumanagara, Jl. Letjen S. Parman No.1 Jakarta \\ Email: alfredsusilo@gmail.com
}

\begin{abstract}
ABSTRAK
Akibat dari pertumbuhan penduduk dan lahan yang semakin terbatas adalah peningkatan harga lahan. Munculnya masalah ini para ahli memberikan solusi untuk membangun hunian vertikal. Meningkatnya kebutuhan tempat tinggal merupakan salah satu faktor yang mempengaruhi ketinggian hunian vertikal. Hal ini mengakibatkan berat gedung yang semakin besar dan fondasi konvensional yang sulit untuk diterapkan. Salah satu solusi yaitu menggunakan fondasi tiang rakit. Fondasi tiang rakit yang telah dikemukakan oleh Burland dkk. (1977), digunakan untuk memikul beban yang berlebihan oleh superstructures seperti pencakar langit. Metode fondasi tiang rakit dikemukakan karena penurunan total dan perbedaan penurunan pada fondasi rakit melebihi batasan izin dan dapat merusak bangunan di atasnya, sehingga ditambahkan tiang untuk mengurangi penurunan total dan perbedaan penurunan tersebut. Akan tetapi pada kondisi di lapangan. Beban aksial yang dipikul pada fondasi rakit sebagian terdistribusi ke tiang. Sehingga menimbulkan desain yang tidak efisien. Pada penilitian ini akan menggunakan rumus empiris dengan analisis parameter tanah untuk memperoleh distribusi beban aksial pada fondasi tiang rakit, dan mengkaji pada bagian perbedaan kedalaman tiang.
\end{abstract}

Kata kunci: Fondasi Rakit, Fondasi Tiang, Penurunan, Daya dukung Tanah, Modulus Kekakuan

\section{PENDAHULUAN}

Fondasi merupakan bagian paling dasar pada suatu struktur bangunan yang berfungsi untuk menyalurkan beban dari bangunan atas ke lapisan tanah dasar. Fondasi sendiri terbagi menjadi dua kelompok yaitu fondasi dangkal dan fondasi dalam. Kedua kelompok fondasi ini masing-masing memiliki keunggulan dan kekurangan, tergantung dengan kebutuhan sebuah bangunan dari segi beban, sifat tanah, kondisi lapangan setempat, dan biaya.

Meningkatnya kebutuhan tempat akan tinggal, merupakan salah satu faktor yang mempengaruhi tinggi gedung hunian vertikal. Hal ini mengakibatkan berat gedung yang semakin besar dan fondasi konvensional sulit untuk diterapkan pada kondisi tanah tertentu. Salah satu solusi dengan menggunakan fondasi tiang rakit, Burland dkk. (1977) mengemukakan fondasi tiang rakit dapat untuk memikul beban berlebihan oleh superstructures seperti pencakar langit. Metode fondasi tiang rakit dikemukakan karena penurunan total dan perbedaan penurunan pada fondasi rakit melebihi batasan izin dan dapat merusak bangunan di atasnya. Sehingga fondasi rakit ditambahkan tiang dengan tujuan mengurangi penurunan total dan perbedaan penurunan. Akan tetapi pada kondisi di lapangan, beban aksial yang dipikul pada fondasi rakit sebagian terdistribusi ke tiang.

\section{Batasan Masalah}

-Analisis daya dukung tanah berdasarkan bangunan dengan kategori gedung bertingkat tinggi dan faktor keamaanan yang telah ditentukan.

-Analisis fondasi tiang rakit berdasarkan laporan data bor log dan hasil penelitian laboratorium pada wilayah Kebayoran Lama, Jakarta Selatan.

-Beban yang akan dianalisis pada penelitian ini adalah gaya aksial, dan tidak memperhitungkan gaya lateral dan momen.

-Spesifikasi fondasi rakit yang digunakan untuk penelitian ini menggunakan ukuran yang seragam.

-Penurunan yang diperhitungkan adalah penurunan elastis dan penurunan konsolidasi primer

\section{Tujuan Penelitian}

Tujuan pada penilitian ini adalah mengunakan rumus empiris dengan analisis parameter tanah untuk memperoleh daya dukung, distribusi beban aksial dan penurnan pada fondasi tiang rakit dan pengujian pada bagian perbedaan 
kedalaman tiang. Sehingga memperoleh kedalaman tiang optimum fondasi tiang rakit pada proyek wilayah kebayoran lama, Jakarta Selatan.

\section{TINJAUAN PUSTAKA}

Seperti fondasi setempat, fondasi rakit berfungsi untuk menyalurkan beban dari bangunan atas ke lapisan tanah. Perbedaan antara kedua fondasi adalah fondasi rakit terbuat dari plat beton yang melebar keseluruh bagian dasar bangunan sedangkan fondasi setempat terbuat dari beton atau batu kali yang berbentuk tapak dan terletak pada masing-masing kolom. Hal ini disebabkan oleh tekanan tanah yang diizinkan pada fondasi setempat terlalu besar sehingga jarak antar fondasi setempat saling berdekatan atau berpotongan. Berbeda dengan fondasi rakit, fondasi tiang digunakan untuk mendukung beban dari bangunan dimana lapisan tanah keras berada sangat dalam, dapat dilihat pada profil tanah tersebut dan tanah pada bagian atas tidak dapat mendukung beban yang disalurkan. Selain mendukung gaya aksial, fondasi tiang juga dapat menahan gaya angkat keatas (uplift). Fondasi Tiang Rakit merupakan jenis fondasi komposit, yang merupakan gabungan antara fondasi tiang dan fondasi rakit. Fondasi ini dikemukakan karena penurunan total dan penurunan diferensial pada fondasi rakit melebihi batas izin dan berbahaya terhadap bangunan di atasnya. Untuk mengatasi hal tersebut fondasi rakit ditambahkan tiang untuk menggurangi penurunan dan menambah kekakuan sistem fondasi, namun penambahan daya dukung fondasi tidak signifikan.

\section{Daya Dukung Fondasi Rakit}

Persamaan yang digunakan untuk menghitung daya dukung tanah fondasi rakit dengan menggunakan metode Terzaghi:

Keterangan

$$
\mathrm{q}_{\text {ult }}=\mathrm{c} \times \mathrm{Nc} \times \mathrm{Sc}+\mathrm{q} \times \mathrm{Nq}+0.5 \times \gamma \times \mathrm{B} \times \mathrm{N} \gamma \times \mathrm{S} \gamma(1)
$$

$\mathrm{q}_{\mathrm{ult}}=$ Daya Dukung Metode Terzaghi $\left[\mathrm{kN} / \mathrm{m}^{2}\right], \mathrm{c}=$ Kohesi $\left[\mathrm{kN} / \mathrm{m}^{2}\right], \gamma=$ Berat Jenis Tanah $\left[\mathrm{kN} / \mathrm{m}^{3}\right]$, $\mathrm{q}=$ Effective Overburden Pressure $=\gamma \mathrm{x}$ Kedalaman, B= Lebar Alas Fondasi [m], Sc, S $\gamma=$ Faktor Bentuk Fondasi, Nc, Nq, N $\gamma=$ Faktor Kapasitas Daya Dukung Terzaghi

Tabel 1 Faktor Bentuk Fondasi (Bowles, Foundation Analysis and Design $5^{\text {th }}$ Edition)

\begin{tabular}{cccc}
\hline For & Strip & Round & Square \\
\hline Sc & 1,0 & 1,3 & 1,3 \\
S $\gamma$ & 1,0 & 0.6 & 0.8 \\
\hline
\end{tabular}

Tabel 2 Faktor Kapasitas Daya Dukung Terzaghi (Bowles, Foundation Analysis and Design $5^{\text {th }}$ Edition) Values of $N_{\gamma}$ for $\phi$ of 0,34 , and $48^{\circ}$ are original Terzaghi values and used to back-compute $\boldsymbol{K}_{\boldsymbol{p y}}$

\begin{tabular}{ccrrr}
\hline $\boldsymbol{\phi}$, deg & \multicolumn{1}{c}{$\boldsymbol{N}_{\boldsymbol{c}}$} & \multicolumn{1}{c}{$\boldsymbol{N}_{\boldsymbol{q}}$} & \multicolumn{1}{c}{$\boldsymbol{N}_{\gamma}$} & $\boldsymbol{K}_{\boldsymbol{p} \gamma}$ \\
\hline 0 & $5.7^{*}$ & 1.0 & 0.0 & 10.8 \\
5 & 7.3 & 1.6 & 0.5 & 12.2 \\
10 & 9.6 & 2.7 & 1.2 & 14.7 \\
15 & 12.9 & 4.4 & 2.5 & 18.6 \\
20 & 17.7 & 7.4 & 5.0 & 25.0 \\
25 & 25.1 & 12.7 & 9.7 & 35.0 \\
30 & 37.2 & 22.5 & 19.7 & 52.0 \\
34 & 52.6 & 36.5 & 36.0 & \\
35 & 57.8 & 41.4 & 42.4 & 82.0 \\
40 & 95.7 & 81.3 & 100.4 & 141.0 \\
45 & 172.3 & 173.3 & 297.5 & 298.0 \\
48 & 258.3 & 287.9 & 780.1 & \\
50 & 347.5 & 415.1 & 1153.2 & 800.0 \\
\hline
\end{tabular}

\section{Daya Dukung Fondasi Tiang}

Tipe fondasi tiang yang akan digunakan dalam penelitian ini adalah tiang bor dan Persamaan yang digunakan untuk menghitung daya dukung pada secara umum adalah:

\section{Keterangan}

$$
\mathrm{Qu}=\mathrm{Qp}+\mathrm{Qs}-\mathrm{Wp}(2)
$$

$\mathrm{Qu}=$ daya dukung ultimit tiang (ton), Qp= daya dukung ultimit ujung tiang (ton), Qs= daya dukung ultimit selimut tiang (ton), $\mathrm{Wp}=$ berat fondasi tiang (ton) 


\section{Analisis Daya Dukung Ujung Tiang}

Persamaan yang digunakan untuk menghitung daya dukung ujung tiang pada penelitian adalah metode Reese \& Wright (1997):

\section{Keterangan}

$$
\mathrm{Qp}=\mathrm{A} \times \mathrm{q}_{\mathrm{p}} / \mathrm{Fk}(3)
$$

$\mathrm{A}=$ luas penampang tiang bor $\left(\mathrm{m}^{2}\right)$, Fk= faktor keamanan, $\mathrm{q}_{\mathrm{p}}=$ tahanan ujung per satuan luasan (ton $/ \mathrm{m}^{2}$ )

Untuk tanah kohesif, besar tahan ujung per satuan luas dan $q_{p}$, diambil sebesar 9 kali kuat geser tanah. Sedangkan untuk tanah non-kohesif, Reese mengusulkan korelasi antara qp dengan Nspt seperti pada Gambar 1

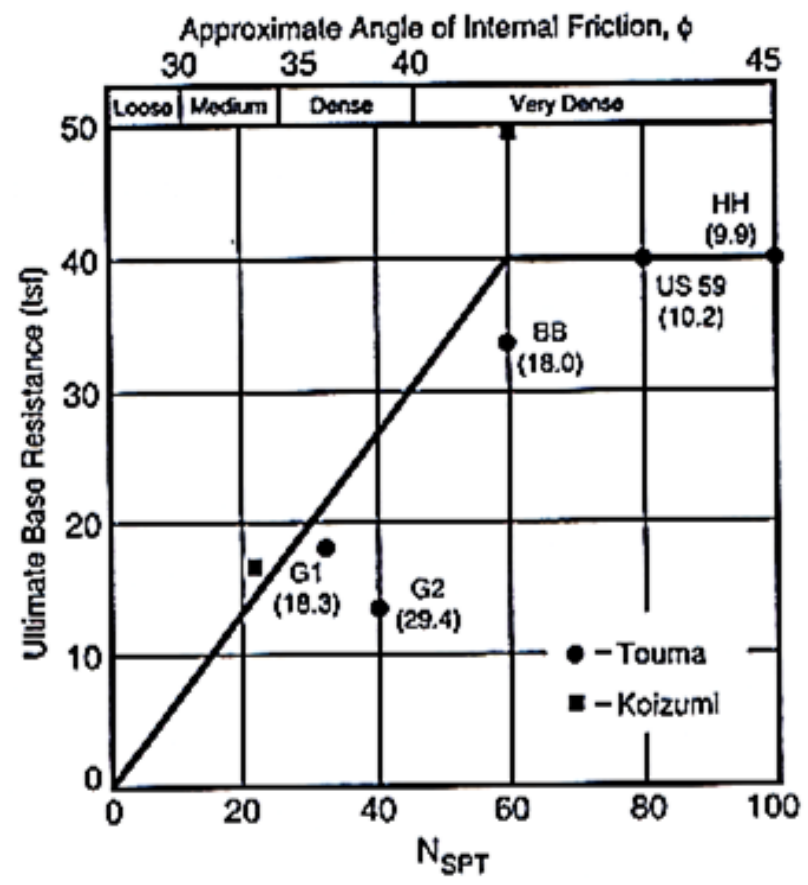

Gambar 1 Tahanan Ujung Ultimit Pada Tanah Non-Kohesif (Reese \& Wright, 1997)

\section{Analisis Daya Dukung Selimut Tiang}

Persamaan yang digunakan untuk menghitung daya dukung selimut tiang pada penelitian adalah metode Reese \& Wright (1997):

\section{Keterangan}

$$
\text { Qs = fs } \times \text { L } \times \text { p / Fk (4) }
$$

fs= gesekan selimut tiang (ton $\left./ \mathrm{m}^{2}\right), \mathrm{L}=$ panjang tiang $(\mathrm{m}), \mathrm{p}=$ keliling penampang tiang $(\mathrm{m})$

Gesekan selimut tiang persatuan luas tiang (fs) dipengaruhi oleh jenis tanah dan parameter kuat geser tanah (Su). Untuk tanah kohesif digunakan rumus:

\section{Keterangan}

$$
\mathrm{fs}=\alpha \times \mathrm{cu}(5)
$$

\section{$\alpha=$ faktor adhesi, $\mathrm{cu}=$ Kohesi tanah (ton $/ \mathrm{m}^{2}$ )}

Berdasarkan penelitian Reese, faktor adhesi $(\alpha)$ dapat diambil sebesar 0,55.

Pada tanah non-kohesif, nilai fs dapat diperoleh dari korelasi langsung dengan Nspt seperti pada Gambar 2 
Tiang Rakit Akibat Perbedaan Kedalaman

Tiang Dan Penurunan

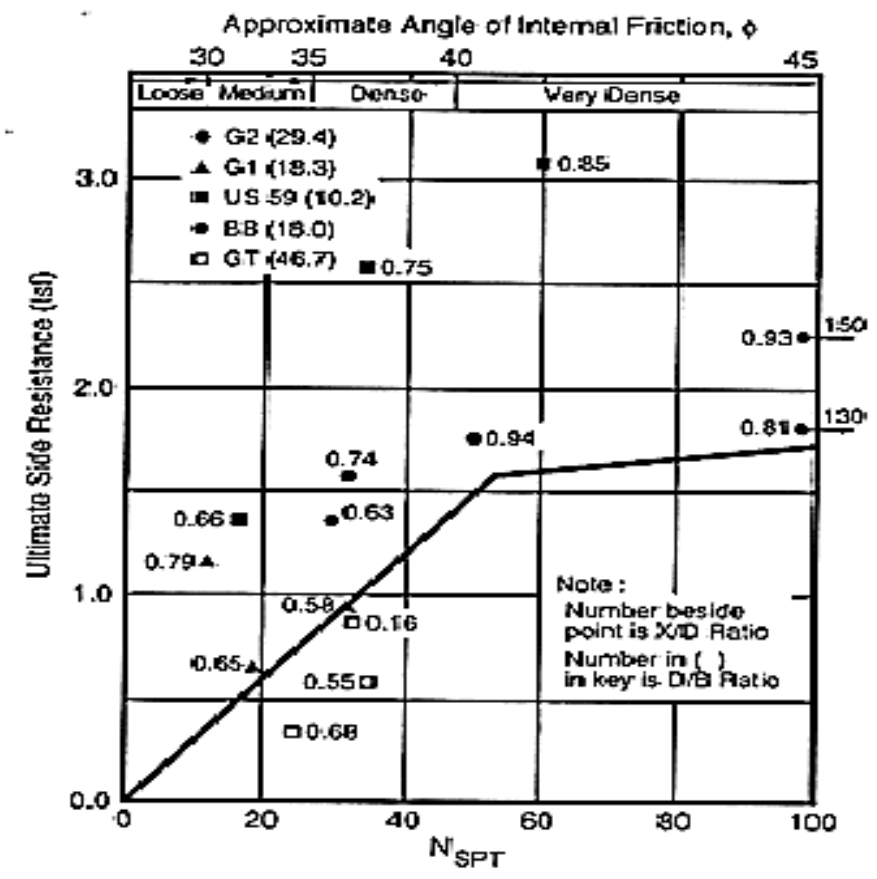

Gambar 2 Hubungan Tahanan Selimut Ultimit Terhadap Nspt pada Tanah Non-Kohesif (Reese \& Wright, 1997)

\section{Penurunan Elastis}

Persamaan yang digunakan untuk mendapatkan penurunan elastis pada penelitian ini merupakan persamaan yang dianjurkan oleh Steinbrenner:

\section{Keterangan}

$$
\text { Se }=\text { qo } \times B^{\prime} \times\left(\left(1-\mu^{2}\right) / E s\right) \times\left(I_{1}+((1-2 \mu) /(1-\mu)) \times I_{2}\right) \times \text { If }(6)
$$

$\mathrm{Se}=$ penurunan elastasis $[\mathrm{m}], \mathrm{qo}=$ tegangan pada dasar lapisan tanah $\left[\mathrm{kN} / \mathrm{m}^{2}\right], \mathrm{B}^{\prime}=$ ukuran paling minim fondasi $[\mathrm{m}]$, $\mu, \mathrm{Es}=$ parameter tanah elastis , $\mathrm{I}_{1}, \mathrm{I}_{2}$, If= faktor pengaruh dari perbandingan L'/B', H dan D sesuai Gambar 3 dan Tabel 2.3

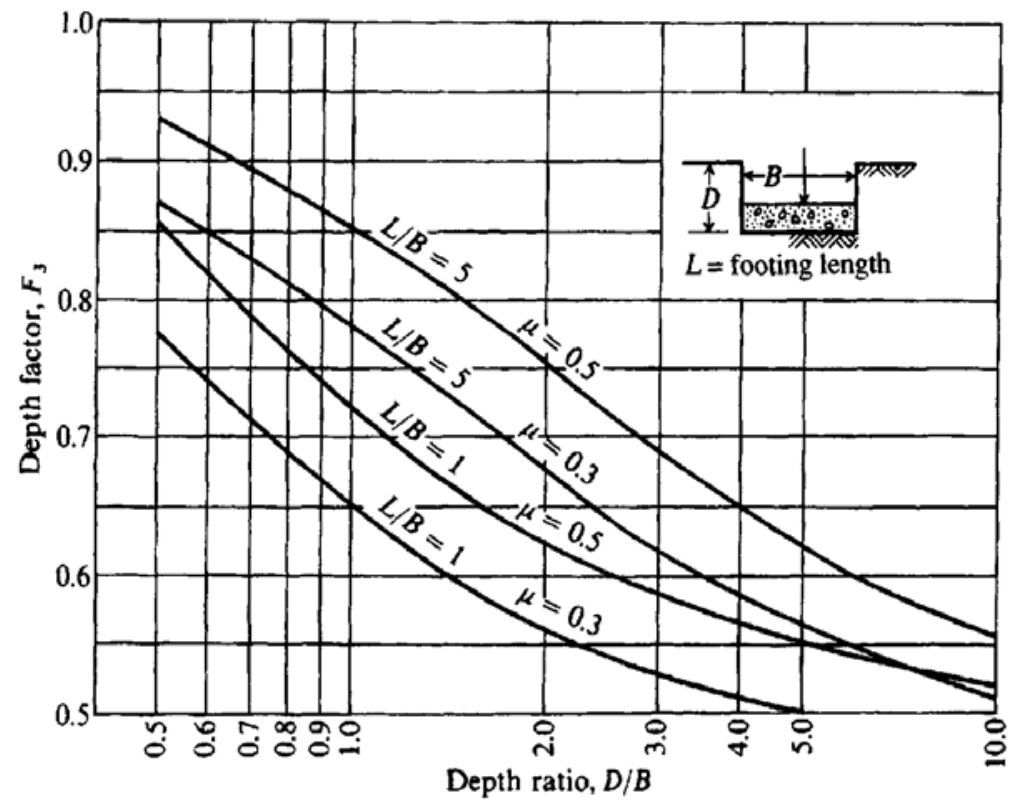

Gambar 3 Faktor pengaruh If akibat kedalaman fondasi (Bowless, 1997:5) 
Tabel 3 Faktor pengaruh $\mathrm{I}_{1}$ dan $\mathrm{I}_{2}$ (Bowles, 1997:5)

\begin{tabular}{|c|c|c|c|c|c|c|c|c|c|c|c|}
\hline$N$ & $M=1.0$ & 1.1 & 1.2 & 1.3 & 1.4 & 1.5 & 1.6 & 1.7 & 1.8 & 1.9 & 2.0 \\
\hline \multirow[t]{2}{*}{0.2} & 0.009 & 0.008 & 0.008 & 0.008 & 0.008 & 0.008 & 0.007 & 0.007 & 0.007 & 0.007 & 0.007 \\
\hline & $l_{2}=0.041$ & 0.042 & 0.042 & 0.042 & 0.042 & 0.042 & 0.043 & 0.043 & 0.043 & 0.043 & 0.043 \\
\hline \multirow[t]{2}{*}{0.4} & 0.033 & 0.032 & 0.031 & 0.030 & 0.029 & 0.028 & 0.028 & 0.027 & 0.027 & 0.027 & 0.027 \\
\hline & 0.066 & 0.068 & 0.069 & 0.070 & 0.070 & 0.071 & 0.071 & 0.072 & 0.072 & 0.073 & 0.073 \\
\hline \multirow[t]{2}{*}{0.6} & 0.066 & 0.064 & 0.063 & 0.061 & 0.060 & 0.059 & 0.058 & 0.057 & 0.056 & 0.056 & 0.055 \\
\hline & 0.079 & 0.081 & 0.083 & 0.085 & 0.087 & 0.088 & 0.089 & 0.090 & 0.091 & 0.091 & 0.092 \\
\hline \multirow[t]{2}{*}{0.8} & 0.104 & 0.102 & 0.100 & 0.098 & 0.096 & 0.095 & 0.093 & 0.092 & 0.091 & 0.090 & 0.089 \\
\hline & 0.083 & 0.087 & 0.090 & 0.093 & 0.095 & 0.097 & 0.098 & 0.100 & 0.101 & 0.102 & 0.103 \\
\hline \multirow[t]{2}{*}{1.0} & 0.142 & 0.140 & 0.138 & 0.136 & 0.134 & 0.132 & 0.130 & 0.129 & 0.127 & 0.126 & 0.125 \\
\hline & 0.083 & 0.088 & 0.091 & 0.095 & 0.098 & 0.100 & 0.102 & 0.104 & 0.106 & 0.108 & 0.109 \\
\hline \multirow[t]{2}{*}{1.5} & 0.224 & 0.224 & 0.224 & 0.223 & 0.222 & 0.220 & 0.219 & 0.217 & 0.216 & 0.214 & 0.213 \\
\hline & 0.075 & 0.080 & 0.084 & 0.089 & 0.093 & 0.096 & 0.099 & 0.102 & 0.105 & 0.108 & 0.110 \\
\hline \multirow[t]{2}{*}{2.0} & 0.285 & 0.288 & 0.290 & 0.292 & 0.292 & 0.292 & 0.292 & 0.292 & 0.291 & 0.290 & 0.289 \\
\hline & 0.064 & 0.069 & 0.074 & 0.078 & 0.083 & 0.086 & 0.090 & 0.094 & 0.097 & 0.100 & 0.102 \\
\hline \multirow[t]{2}{*}{3.0} & 0.363 & 0.372 & 0.379 & 0.384 & 0.389 & 0.393 & 0.396 & 0.398 & 0.400 & 0.401 & 0.402 \\
\hline & 0.048 & 0.052 & 0.056 & 0.060 & 0.064 & 0.068 & 0.071 & 0.075 & 0.078 & 0.081 & 0.084 \\
\hline \multirow[t]{2}{*}{4.0} & 0.408 & 0.421 & 0.431 & 0.440 & 0.448 & 0.455 & 0.460 & 0.465 & 0.469 & 0.473 & 0.476 \\
\hline & 0.037 & 0.041 & 0.044 & 0.048 & 0.051 & 0.054 & 0.057 & 0.060 & 0.063 & 0.066 & 0.069 \\
\hline
\end{tabular}

$\mathrm{B}^{\prime}=\mathrm{B} / 2$ untuk penurunan pada tengah fondasi $=\mathrm{B}$ untuk tepi fondasi $\mathrm{Ii}, \mathrm{L}$ '= $\mathrm{L} / 2$ untuk penurunan pada tengah fondasi $=\mathrm{L}$ untuk tepi fondasi Ii, $\mathrm{N}=\mathrm{H} / \mathrm{B}^{\prime}, \mathrm{M}=\mathrm{L} / \mathrm{B}$

\section{Penurunan Konsolidasi Primer}

Persamaan penurunan konsolidasi primer dibagi menjadi dua, yaitu terkonsolidasi normal (NC) dan terkonsolidasi berlebih (OC). Konsolidasi normal terjadi jika tegangan dasar pada lapisan yang ditinjau lebih kecil dari tegangan konsolidasi dan kebalikan konsolidasi berlebihan (Coduto, 2001:2).

Untuk terkonsolidasi normal:

Untuk terkonsolidasi berlebih:

$$
\mathrm{Sp}=\left((\mathrm{Cc} \times \mathrm{H}) /\left(1+\mathrm{e}_{0}\right)\right) \times\left(\log \left(\left(\mathrm{p}^{\prime}{ }_{\mathrm{o}}+\Delta \mathrm{P}\right) / \mathrm{p}^{\prime}{ }_{\mathrm{o}}\right)\right)(7)
$$

$$
\mathrm{Sp}=\left((\mathrm{Cs} \times \mathrm{H}) /\left(1+\mathrm{e}_{0}\right)\right) \times\left(\log \left(\left(\mathrm{p}^{\prime}{ }_{\mathrm{o}}+\Delta \mathrm{P}\right) / \mathrm{p}^{\prime}{ }_{\mathrm{o}}\right)\right)(8)
$$

Keterangan

$\mathrm{Sp}=$ penurunan konsolidasi primer $[\mathrm{m}], \mathrm{Cc}=$ index kompresi, $\mathrm{Cs}=$ swelling index, $\mathrm{H}=$ tebal lapisan $[\mathrm{m}], \mathrm{e}_{\mathrm{o}}=$ initial void ratio, $\mathrm{p}^{\prime}{ }_{\mathrm{o}}=$ tegangan efektif $\left[\mathrm{kN} / \mathrm{m}^{2}\right], \Delta \mathrm{P}=$ tegangan pada lapisan ketika terbebani $\left[\mathrm{kN} / \mathrm{m}^{2}\right]$

\section{METODOLOGI PENELITIAN}

Dalam penelitian terdapat beberapa tahapan yang diuraikan sebagai berikut:

Tahapan Pertama adalah mengumpulkan data penyelidikan tanah in-situ dan laboratorium.

Tahapan Kedua adalah mengalisis kapasistas fondasi rakit dan fondasi tiang dengan faktor keamanan yang telah ditentukan.

Tahapan Ketiga adalah menganalisis distribusi beban sesuai SNI 8460:2017.

Tahapan Keempat menganalisis kebutuhan dengan distribusi beban dan pembahan kedalaman tiang.

Tahapan Kelima menganalisis penurunan dari masing-masing distribusi beban dan kedalaman tiang.

Tahapan Keenam mencari kedalaman tiang optimum pada fondasi tiang rakit. 


\section{ANALISIS DATA DAN HASIL}

\section{Data Parameter Tanah}

Setelah didapatkan parameter tanah dari pengujian lapangan, laboratorium, dan korelasi. Parameter tersebut akan digabung menjadi satu kesatuan dengan engineering adjustment yang akan digunakan dalam mendesain perkerjaan geoteknik.

\section{Daya Dukung Fondasi Rakit}

Nilai daya dukung fondasi rakit diperoleh dengan menggunakan rumus 1 Pada contoh perhitungan daya dukung fondasi rakit sebagai berikut:

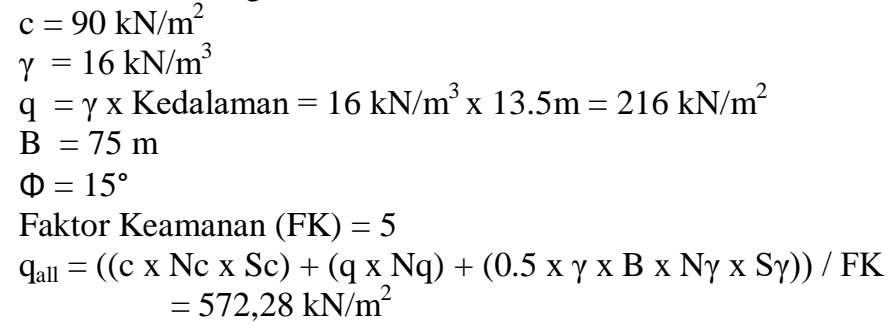

\section{Daya Dukung Fondasi Tiang}

Dari hasil analisis dengan rumus yang dikemukan oleh Reese and Wright (1997) diperoleh daya dukung masing tiang sebesar pada Tabel 5

Tabel 5 Kapasistas Daya Dukung Tiang

\begin{tabular}{ccc}
\hline Tipe Fondasi & \multicolumn{2}{c}{ Kedalaman (m) } \\
\hline Diameter Bor Pile & DB1-DB2 30m $(\mathrm{kN})$ & DB3-DB4 30m $(\mathrm{kN})$ \\
\hline$\Phi 0.3 \mathrm{~m}$ & 409.60 & 377.79 \\
$\Phi 0.4 \mathrm{~m}$ & 550.16 & 496.75 \\
$\Phi 0.5 \mathrm{~m}$ & 692.72 & 612.22 \\
$\Phi 0.6 \mathrm{~m}$ & 837.30 & 724.20 \\
\hline
\end{tabular}

\section{Asumsi Beban Bangunan}

Beban Bangunan yang diasumsi untuk penelitian ini adalah sebesar 508839.41 Ton.

Tabel 6 Berat Total Bangunan

\begin{tabular}{lc}
\hline JENIS BEBAN & BERAT (TON) \\
\hline Balok Induk Arah X & 28771.2 \\
Balok Induk Arah Y & 13486.5 \\
Balok Anak & 8991 \\
Core Wall & 7032.96 \\
Kolom & 43956 \\
Pelat Dead Load & 249750 \\
Berat Spesi 2cm & 34650 \\
Berat Ubin & 19800 \\
Berat Dinding & 45237.5 \\
Penutup Langit & 9075 \\
Mechanical \& Electrical & 12375 \\
Pelat Live Load & 35714.25
\end{tabular}


Jurnal Mitra Teknik Sipil

Vol. 2, No. 4, November 2019: hlm 122-132

EISSN 2622-545X

Total

508839.41 


\begin{tabular}{|c|c|c|c|c|c|c|c|c|c|c|c|c|c|}
\hline Depth (m) & Legend & $\gamma\left(\mathrm{kN} / \mathrm{m}^{3}\right)$ & $\sigma \mathrm{v}\left(\mathrm{kN} / \mathrm{m}^{2}\right)$ & $\sigma v^{\prime}\left(k N / m^{2}\right)$ & $\mathrm{Su}\left(\mathrm{kN} / \mathrm{m}^{2}\right)$ & LL & Cc & Cs & $\mathrm{e}_{0}$ & $P c^{\prime}\left(\mathrm{kN} / \mathrm{m}^{2}\right)$ & ocr & Es (Mpa) & $\mu_{\mathrm{s}}$ \\
\hline-2 & $\mathrm{CH}$ & 15 & 30 & 10 & 35 & 105.00 & 0.86 & 0.15 & 2.74 & 129.40 & 12.94 & 5 & 0.4 \\
\hline-3 & ML & 15 & 45 & 15 & 35 & 100.00 & 0.60 & 0.11 & 2.38 & 304.00 & 20.27 & 7.5 & 0.4 \\
\hline-4 & $\mathrm{CH}$ & 15 & 60 & 20 & 10 & 85.00 & 0.68 & 0.10 & 1.34 & 115.00 & 5.75 & 7.5 & 0.3 \\
\hline-15.5 & ML & 15 & 232.5 & 77.5 & 35 & 64.00 & 0.49 & 0.02 & 1.33 & 129.4 & 1.67 & 20 & 0.3 \\
\hline-25 & MH-SP & 15 & 375 & 125 & $\# N / A$ & $\# N / A$ & $\# N / A$ & $\# N / A$ & 0.91 & $\# N / A$ & $\# N / A$ & 25 & 0.35 \\
\hline-28.5 & CH-SP & 15 & 427.5 & 142.5 & $\# N / A$ & $\# N / A$ & $\# N / A$ & $\# N / A$ & 1.92 & $\# N / A$ & $\# N / A$ & 24 & 0.3 \\
\hline-30 & SP & 15 & 450 & 150 & $\# N / A$ & $\# N / A$ & $\# N / A$ & $\# N / A$ & 1.10 & $\# N / A$ & $\# N / A$ & 24 & 0.4 \\
\hline-36 & ML & 17 & 552 & 192 & 47 & 61.00 & 0.80 & 0.24 & 2.05 & 657.04 & 3.42 & 13 & 0.4 \\
\hline-42.5 & ML & 17 & 662.5 & 237.5 & 50 & 66.00 & 0.50 & 0.15 & 1.67 & 186.1 & 0.78 & 14 & 0.2 \\
\hline-47 & SP & 17 & 739 & 269 & $\# N / A$ & $\# N / A$ & $\# N / A$ & $\# N / A$ & 1.05 & $\# N / A$ & $\# N / A$ & 50 & 0.3 \\
\hline-50.5 & ML & 17 & 798.5 & 293.5 & 80 & 54.00 & 0.40 & 0.03 & 0.96 & 299.50 & 1.02 & 14 & 0.31 \\
\hline-54.5 & $\mathrm{CH}$ & 17 & 866.5 & 321.5 & 200 & 78.00 & 0.63 & 0.04 & 0.85 & 745.30 & 2.32 & 30 & 0.44 \\
\hline-61.5 & $\mathrm{CH}$ & 17 & 985.5 & 370.5 & 340 & 62.80 & 0.48 & 0.03 & 1.10 & 1282.30 & 3.46 & 28 & 0.45 \\
\hline-69 & $\mathrm{CH}$ & 17 & 1113 & 423 & 120 & 66.05 & 0.50 & 0.04 & 1.01 & 450.70 & 1.07 & 32 & 0.42 \\
\hline-74.5 & ML & 17 & 1206.5 & 461.5 & 95 & 68.30 & 1.25 & 0.09 & 1.45 & 549.17 & 1.19 & 20 & 0.32 \\
\hline-80 & MH & 17 & 1300 & 500 & 90 & 95.30 & 0.77 & 0.05 & 1.40 & 843.37 & 1.69 & 20 & 0.35 \\
\hline-90 & ML & 17 & 1470 & 570 & 100 & 76.00 & 0.97 & 0.07 & 1.08 & 1108.15 & 1.94 & 20 & 0.34 \\
\hline-100 & ML & 17 & 1640 & 640 & 120 & 61.16 & 0.46 & 0.03 & 1.02 & 450.70 & 0.70 & 20 & 0.35 \\
\hline
\end{tabular}

Keterangan $=\# N / A=$ Not Applicable

Tabel 4 Resume Design Parameter Tanah 


\section{Distribusi Beban}

Pada perhitungan jumlah tiang dan penurunan, distribusi beban dibagi menjadi dua kombinasi. Kombinasi pertama adalah beban yang diterima fondasi rakit sebesar 75\% dan fondasi tiang sebesar 25\%, dan kombinasi kedua merupakan kebalikan dari tahap pertama dimana beban diterima fondasi rakit sebesar 25\% dan fondasi tiang sebesar 75\%. Pembuktian distribusi beban akan diperoleh dari analisis program.

\section{Jumlah Tiang}

Dari hasil analisis dengan kombinasi masing-masing distribusi dan penambahan kedalaman tiang, diperoleh jumlah tiang seperti pada Tabel 7 dan Tabel 8.

Tabel 7 Jumlah Tiang Tahap 1

\begin{tabular}{cccc}
\hline $\begin{array}{c}\text { Kedalaman } \\
(\mathrm{m})\end{array}$ & $\begin{array}{c}\text { Panjang } \\
\text { Tiang } \\
(\mathrm{m})\end{array}$ & $\begin{array}{c}\text { Kapasitas } \\
\text { Tiang } \\
(\mathrm{kN})\end{array}$ & $\begin{array}{c}\text { Jumlah } \\
\text { Tiang }\end{array}$ \\
\hline-19 & 6 & 307.88 & 4052 \\
-20 & 7 & 346.36 & 3602 \\
-21 & 8 & 384.85 & 3242 \\
-22 & 9 & 423.33 & 2947 \\
-23 & 10 & 461.81 & 2702 \\
-24 & 11 & 500.30 & 2494 \\
-25 & 12 & 538.78 & 2316 \\
-26 & 13 & 577.27 & 2161 \\
-27 & 14 & 615.75 & 2026 \\
-28 & 15 & 654.24 & 1907 \\
-29 & 16 & 692.72 & 1801 \\
-30 & 17 & 707.64 & 1763 \\
\hline
\end{tabular}

Tabel 8 Jumlah Tiang Tahap 2

\begin{tabular}{cccc}
\hline $\begin{array}{c}\text { Kedalaman } \\
(\mathrm{m})\end{array}$ & $\begin{array}{c}\text { Panjang } \\
\text { Tiang } \\
(\mathrm{m})\end{array}$ & $\begin{array}{c}\text { Kapasitas } \\
\text { Tiang } \\
(\mathrm{kN})\end{array}$ & $\begin{array}{c}\text { Jumlah } \\
\text { Tiang }\end{array}$ \\
\hline-19 & 6 & 307.88 & 12156 \\
-20 & 7 & 346.36 & 10805 \\
-21 & 8 & 384.85 & 9725 \\
-22 & 9 & 423.33 & 8841 \\
-23 & 10 & 461.81 & 8104 \\
-24 & 11 & 500.30 & 7481 \\
-25 & 12 & 538.78 & 6946 \\
-26 & 13 & 577.27 & 6483 \\
-27 & 14 & 615.75 & 6078 \\
-28 & 15 & 654.24 & 5721 \\
-29 & 16 & 692.72 & 5403 \\
-30 & 17 & 707.64 & 5289 \\
\hline
\end{tabular}

\section{Perbandingan Penurunan}

Dengan semua analisis yang dilakukan sebelumnya, dapat dihitung besar penunurunan fondasi tiang rakit dengan distribuis beba dan penambahan kedalaman tiang sepertu pada Tabel 9 dan Tabel 10.

Tabel 9 Total Penurunan Fondasi Tiang Rakit Kombinasi Pertama

\begin{tabular}{cccc}
\hline Pile Length $(\mathrm{m})$ & Pile Settlement $(\mathrm{mm})$ & Raft Settlement $(\mathrm{mm})$ & Total Settlement $(\mathrm{mm})$ \\
\hline 7 & 37.35 & 234.54 & 271.89 \\
8 & 32.61 & 234.54 & 267.15 \\
9 & 27.87 & 234.54 & 262.41 \\
10 & 33.00 & 234.54 & 267.54 \\
11 & 33.06 & 234.54 & 267.59 \\
12 & 33.12 & 234.54 & 267.65 \\
13 & 33.18 & 234.54 & 267.71 \\
14 & 33.24 & 234.54 & 267.77 \\
15 & 33.30 & 234.54 & 267.83 \\
16 & 33.35 & 234.54 & 267.89 \\
17 & 33.39 & 234.54 & 267.92 \\
18 & 33.47 & 234.54 & 268.01 \\
19 & 33.53 & 234.54 & 268.07 \\
20 & 41.80 & 234.54 & 276.34 \\
\hline
\end{tabular}


Analisis Distribusi Gaya Aksial Pada Fondasi

Jovito Charless, et al.

Tiang Rakit Akibat Perbedaan Kedalaman

Tiang Dan Penurunan

\begin{tabular}{cccc}
\hline Pile Length $(\mathrm{m})$ & Pile Settlement $(\mathrm{mm})$ & Raft Settlement $(\mathrm{mm})$ & Total Settlement $(\mathrm{mm})$ \\
\hline 34 & 188.1179914 & 89.77 & 277.89 \\
35 & 185.560566 & 89.77 & 275.33 \\
36 & 183.0030236 & 89.77 & 272.77 \\
37 & 180.4453658 & 89.77 & 270.21 \\
38 & 177.8875942 & 89.77 & 267.66 \\
39 & 175.3297105 & 89.77 & 265.10 \\
40 & 172.7717164 & 89.77 & 262.54 \\
\hline
\end{tabular}

Tabel 10 Total Penurunan Fondasi Tiang Rakit Kombinasi Keuda
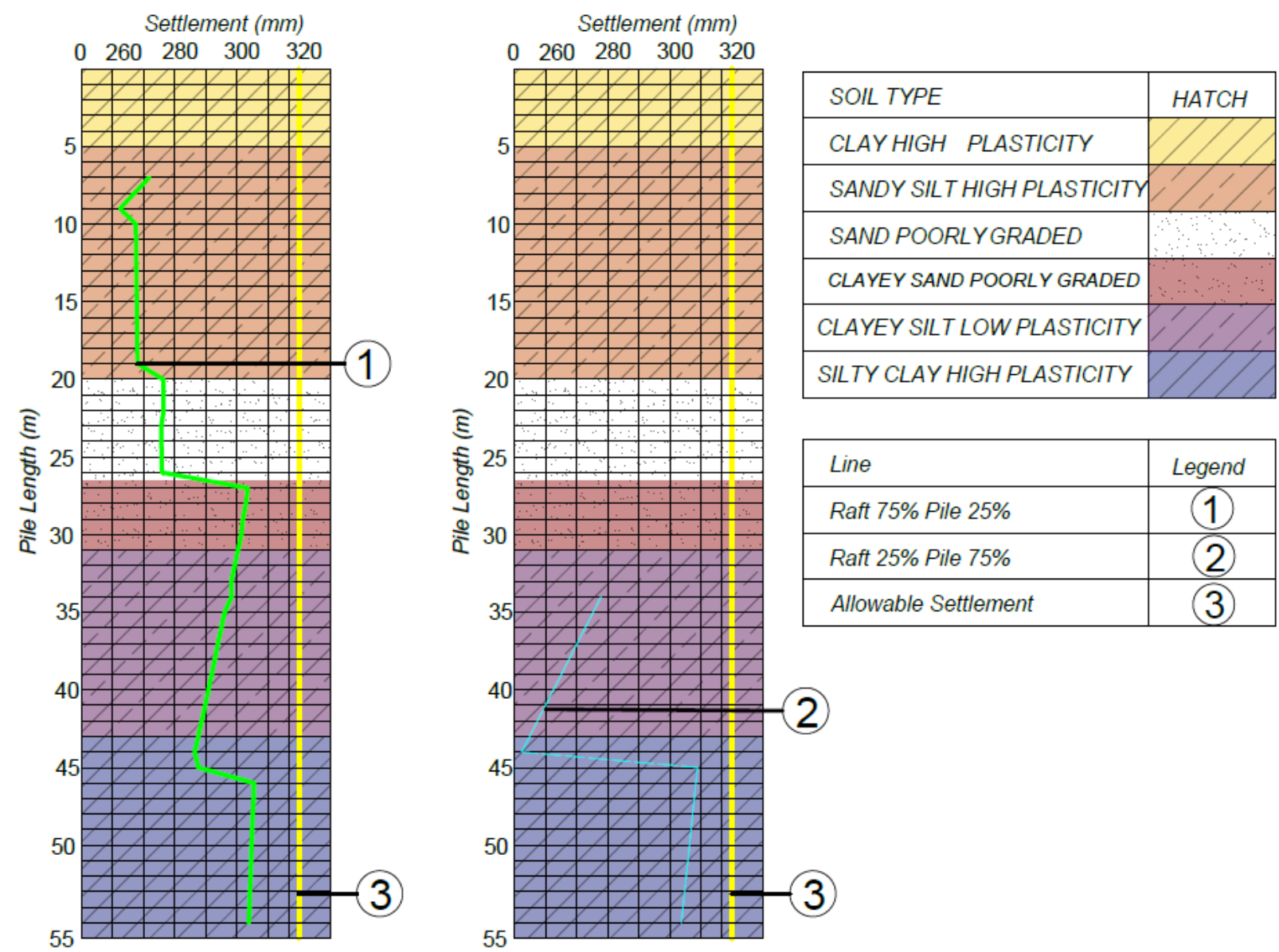

Gambar 4 Penurunan Fondasi Tiang Rakit dengan Penambahan Kedalaman Tiang

\section{KESIMPULAN}

Dari analisis daya dukung fondasi rakit, fondasi tiang, jumlah tiang dengan perbedaan kedalaman, dan penurunan yang telah dilakukan, dapat disimpulkan seperti terlihat pada Gambar 4 dan Tabel 4:

1. Pengurangan penurunan fondasi tiang rakit tidak selalu signifikan dengan bertambahnya kedalaman tiang. 
2. Pada distribusi beban fondasi rakit $75 \%$ dan fondasi tiang $25 \%$, tidak terdapat penurunan signifikan pada kedalaman tiang 10 s.d. $17 \mathrm{~m}$ dan 20 s.d. 26 m dikarenakan lapisan pasir terletak dibawa 2/3 panjang tiang sehingga tidak mengalami penurunan elastis.

3. Pada distribusi beban fondasi rakit $25 \%$ dan fondasi tiang $75 \%$, penurunan berkurang dengan penambahan kedalaman tiang, ini dikarenakan kedalaman tiang yang dibutuhkan untuk kombinasi tersebut telah melewati lapisan pasir sehingga lapisan pasir hanya mengalami penurunan elastis namu tidak mengalami konsolidasi.

4. Dengan penambahan kedalaman tiang, lapisan pasir yang masuk ke zona 2/3L tiang, penurunan bertambah 10 s.d. $20 \mathrm{~mm}$, ini disebabkan oleh lapisan pasir yang terjadi penurnan elastis.

5. Total penurunan dari kedua distribusi beban berpotongan pada kedalaman 54m, dengan penurnan sebesar $303.23 \mathrm{~mm}$

\section{DAFTAR PUSTAKA}

Bowles, Joseph E, Foundation Analysis and Design $5^{\text {th }}$ Edition, Illinois: The Mac Graw-Hill Companies, 1997. Coduto, Donald P., Foundation Design Principle and Practice $2^{\text {nd }}$ Edition, Pomona: Prentice Hall, 2001.

Deep Foundation Research Institute Parahyangan Catholic University, Manual Fondasi Tiang $4^{\text {th }}$ Edition, Universitas Katolik Parahyangan, 2013. 
Analisis Distribusi Gaya Aksial Pada Fondasi

Jovito Charless, et al.

Tiang Rakit Akibat Perbedaan Kedalaman

Tiang Dan Penurunan 